\title{
Consumer preferences for iced coffee determined by conjoint analysis: an exploratory study with Norwegian consumers
}

Article

Accepted Version

Asioli, D., Næs, T., Granli, B. S. and Almli, V. L. (2014) Consumer preferences for iced coffee determined by conjoint analysis: an exploratory study with Norwegian consumers. International Journal of Food Science \& Technology, 49 (6). pp. 1565-1571. doi: https://doi.org/10.1111/ijfs. 12485 Available at http://centaur.reading.ac.uk/76530/

It is advisable to refer to the publisher's version if you intend to cite from the work. See Guidance on citing.

To link to this article DOI: http://dx.doi.org/10.1111/ijfs.12485 
including copyright law. Copyright and IPR is retained by the creators or other copyright holders. Terms and conditions for use of this material are defined in the End User Agreement.

\section{www.reading.ac.uk/centaur}

\section{CentAUR}

Central Archive at the University of Reading

Reading's research outputs online 
TITLE:

Consumer preferences for iced coffee determined by conjoint analysis:

An exploratory study with Norwegian consumers

\section{SUMMARY}

10 The main aim of this paper is to investigate consumer preferences for extrinsic attributes of iced coffee, 11 explore consumers' coffee consumption habits, find new market opportunities and segment consumers 12 based on similar products preferences. A sample of 101 consumers of iced coffee was recruited during 132012 in Norway. Twelve iced coffee products combining different levels of attributes: coffee type, origin, 14 calories and price were presented on screen and rated according to consumers' willingness to buy (WTB). 15 Mixed Model ANOVA, Principal Component Analysis (PCA) and Partial Least Squares Discriminant 16 Analysis (PLS-DA) were applied to analyze data. Results show that the most preferred products for the 17 consumer sample as a whole were low price - low calorie products while age has a significant effect on 18 WTB for different iced coffee products. Four different consumer segments based on type of iced coffee 19 and country of production preferences were identified and discussed.

\section{KEYWORDS}

22 Iced coffee, Conjoint Analysis, Rating, Willingness to buy, Consumers preference, Segmentation, 23 Norway.

\footnotetext{
${ }^{1}$ Corresponding author: Tel: + 47649701 65; Fax: +47 64970333 .

Email: daniele.asioli@nofima.no
} 


\section{Running title: CONSUMER PREFERENCES FOR ICED COFFEE PRODUCTS}

\section{INTRODUCTION}

Iced coffee is now increasing its consumption in Scandinavian countries which have the world's highest levels of coffee consumption (International Coffee Organisation, 2011). Since the early 1980s, iced coffee has been very popular in the USA, Greece and Japan as a refreshing drink where it is usually drunk in small bottles for take-away consumption, or enjoyed for quenching thirst while sitting outside at a café (Petit \& Sieffermann, 2007). In 1999 one of the main Norwegian food companies started introducing various types of iced coffee on the food market, and several other brands have followed since this product category has grown in popularity in the recent years. As the iced coffees on the Norwegian market do not have much variety except for the different types of coffee, more information is needed for understanding consumer preferences and choice attributes for this type of product. In addition, since Norwegian consumers have sensory experience with iced coffee, it is highly relevant to consider the impact of various factors such as nutritional, economic, ethnocentric and sensory properties. To the best knowledge of the authors, no studies are available which investigate the consumption of iced coffee in Norway, with particular reference to extrinsic factors affecting consumption. Petit \& Sieffermann (2007) investigated the effect of the physical testing environment on liking and consumption of iced coffee by French consumers. With regard to consumer motivations and attitudes, there is a general lack of studies that investigate consumer preferences and motivation for coffee consumption (Rozin \& Cines, 1982), with the exception of fair trade or environmentally friendly coffee (De Pelsmacker, et al., 2005; Raynolds, 2004).

One of the most applied predictive statistical model which determine consumer response towards different product profiles is Conjoint Analysis (Annunziata \& Vecchio, 2013; De Pelsmaeker, Dewettinck, \& Gellynck, 2013; Saito \& Saito, 2013). CA is defined as a method for analyzing the effect of a number of designed factors (e.g. packaging, information factors, etc.) on consumer acceptance or choice (Næs, Brockhoff, \& Tomic, 2010). CA includes a set of techniques able to measure buyers' tradeoffs among multiattribute products or services, including foods (Claret et al., 2012; Cox, et al., 2007; Næs, et al., 2010; Næs, et al., 2010a). CA is used to estimate the structure of consumer evaluations on a set of product profiles consisting in predetermined combinations of product attributes (Green \& 


\section{Running title: CONSUMER PREFERENCES FOR ICED COFFEE PRODUCTS}

51 Srinivasan, 1978). In this paper, we will use Willingness To Buy (WTB) ratings collected on a 9-point 52 category scale ranging from 1 "I would definitely not buy" to 9 "I will definitely buy". In CA, relating 53 consumer preferences to individual differences in demographics, attitudes, habits, etc. is important, 54 because it helps to understand consumer behaviour and provides useful information for improving the 55 process of product development and developing targeted marketing strategies (Endrizzi, Menichelli, 56 Johansen, Olsen, \& Næs, 2011). The data presented in this paper are extracted from a large consumer 57 experiment conducted in Norway during autumn 2012. In particular, this paper investigates consumers' 58 preferences for iced coffee varying in several extrinsic attributes. This information is particularly useful 59 for iced coffee producers in Scandinavia, considering Scandinavia have the world's highest levels of 60 consumption. In the present paper, only the data concerning the rating group of participants will be 61 investigated.

63 The paper addresses four questions: (i) What type of iced coffee attributes increases consumers' 64 willingness to buy, (ii) Are coffee consumption habits related to iced coffee consumption habits, (iii) Do 65 conjoint experimental results match self-reported purchase habits for iced coffee and (iv) What are the main iced coffee preference (WTB) segments and who are the people in each of these segments. To

67 achieve this goals the study was organized in two complementary steps: (i) a qualitative approach and (ii) 68 a quantitative approach. The qualitative approach aimed to identify, by means of, which attributes and 69 levels were considered the most relevant in a decision-making process when choosing iced coffee. The 70 quantitative approach applied CA to determine consumer preference for the different levels of the 71 selected attributes, and the relative importance that these attributes have for iced coffee buyers. The 72 quantitative study was completed with a socio-demographic, attitudinal and behavioural questionnaire 73 focusing in particular on iced coffee and (warm) coffee consumption habits.

\section{MATERIAL AND METHODS}

76 Focus group: selection of attributes and levels 


\section{Running title: CONSUMER PREFERENCES FOR ICED COFFEE PRODUCTS}

77 A discussion was carried out in October 2012 in the South of Norway, in order to identify the most 78 relevant attributes that Norwegian consumers take into account when purchasing iced coffee. The 79 participants were 10 people $(\mathrm{N}=10)$ aged between 21 and 56 years Consumers were selected based on 80 three main criteria: age, gender and frequency of buying/drinking iced coffee. The FG was basically 81 structured in two different topics. The first topic concerned the description of situation of buying/drinking 82 iced coffee, such as motivations for buying/drinking, location, type of outlet, alone/with other people, 83 time of the day, flavors, prices, brands, packaging and quantity. The second topic regarded the 84 characteristics of a typical iced coffee drinker, such as age, lifestyle, etc. The FG discussion was 85 conducted by an experienced moderator while an assistant took notes. The most relevant attributes and 86 levels from a consumer perspective were identified and selected to design the conjoint study. Moreover, 87 the FG provided inputs on iced coffee consumption habits that were used to develop the conjoint study.

\section{Conjoint study}

\section{$90 \quad$ Participants}

91 A sample of 101 consumers $(\mathrm{N}=101)$ were recruited in the region South of Oslo (Norway) in November 922012 with an on-line recruitment questionnaire using the EyeQuestion system (Logic8 BV, The 93 Netherlands). Consumers were recruited according to three main criteria: usage frequency of iced coffee, 94 gender and age. Regular consumers of iced coffee aged between 20 and 60 years were selected to take 95 part in the experiment. Finally, for each participating consumer a reward of NOK 300 was attributed to 96 the leisure time organization or club of their choice.

\section{Consumer test}

99 The consumer test was held in the sensory lab of Nofima (Ås, Norway) and included four sessions. In the 100 introductory session, a sample of iced coffee was served to the consumers in neutral plastic cups in order 101 to focus the consumers on the product as a warm up sample. In the second session, the conjoint task, 102 consumers rated their probability of buying for different iced coffee profiles presented on screen in the 


\section{Running title: CONSUMER PREFERENCES FOR ICED COFFEE PRODUCTS}

form of mock-up products. This session is described in details below. The third session involved hedonic

ratings on iced coffee samples and is not investigated in this paper. The last session consisted in a questionnaire investigating the consumers' consumption habits for coffee and iced coffee (frequency, location, usage of cream/sugar, etc.) and some socio-demographic characteristics. The participants were seated in separate booths. Data collection was performed on individual computers in the EyeQuestion system (Logic8 BV, The Netherlands).

\section{Selection of iced coffee attributes and levels: conjoint analysis design and iced coffee samples}

Based on the results obtained from the FG attributes were selected: coffee type, calories, origin and price. Regarding coffee type, two different levels were chosen: "Espresso" and "Latte" as they are among the most frequently consumed coffee types in Norway and they represent two distinct strengths of coffee taste. With concern to the calories, the FG discussion highlighted the importance of calories in consumer choice especially for older consumers. The two levels of calories ("60" and "90 kcal/100 ml") were chosen based on typical calorie levels of iced coffee products that are present on the market. Concerning the country of origin two levels were chosen: "Norway" as the market leader is a Norwegian company, and "Italy" due to its high reputation for coffee products. Finally, as purchasing prices three different levels were chosen, thus representing the high, middle and low end of the prices in the Norwegian market for iced coffee products ("NOK 17", "NOK 23" and "NOK 29", approximately from $€ 2.2, € 3$ and $€ 3.8$ per unit). Full factorial design was not appropriate in the present study due to the large number of possible factor and level combinations $(2 \times 2 \times 2 \times 3=24)$ that should be presented to consumers. In order to effectively test the attribute effects on buyer's preference while reducing the number of product profiles presentations, a fractional factorial design of 12 hypothetical products was constructed (Table 1). This orthogonal array design was created by using the statistical package SAS version 9.3.

\section{Conjoint analysis data collection}




\section{Running title: CONSUMER PREFERENCES FOR ICED COFFEE PRODUCTS}

128 Photographs of 12 mock-up products, one for each product profile were created and presented 129 monadically on computer screen and following a balanced randomized order across consumers. Prior to 130 the task, a standard profile picture was shown pointing at the four attributes of interest (only indicating 131 "country", "price", "calories" and "coffee type" without any specific level) in order to make participants 132 aware of the location of relevant information on the pictures. For each picture, consumers' probability of 133 buying was elicited with the question: "Imagine that you are purchasing iced coffee. How likely is it that 134 you would buy this particular iced coffee?". Answers were gathered on a 9-point scale from 1 (Extremely 135 unlikely) to 9 (Extremely likely).

\section{Statistical data analysis}

138 The conjoint rating data were analysed with the purpose to identify significant effects at population level, 139 then define and characterise consumer segments based on individual preferences. This was achieved by 140 applying the following statistical models: Mixed Model ANOVA, Principal Component Analysis (PCA) 141 and Partial Least Squares Discriminant Analysis (PLS-DA).

\section{2}

\section{Mixed model ANOVA}

144 In conjoint experiments based on rating scales, the population effects from consumer evaluations are 145 typically analyzed by mixed model ANOVA (Næs et al., 2010). This model includes Calories, Coffee, 146 Origin and Price as main effects, and of the six possible two-way interaction effects the following four 147 were included: Price*Calories, Coffee*Calories, Calories* Origin and Price*Coffee. These main effects 148 and interactions were included as fixed factors, while a Consumer effect was included as random factor. 149 Furthermore, random interaction effects between Consumer and the four factors were included to account 150 for individual preferences. The model is written: 
Running title: CONSUMER PREFERENCES FOR ICED COFFEE PRODUCTS 


\section{Running title: CONSUMER PREFERENCES FOR ICED COFFEE PRODUCTS}

The four main drivers that lead consumers to drinking iced coffee are "I want to indulge myself" followed by "It will keep me awake" and "I need new energy (Figure 1). Therefore consumers' main motivations for iced coffee consumption are enjoyment and relaxation, as well as energy and caffeine intake.

\section{Most preferred iced coffee products}

In order to identify the most preferred type of iced coffee for the consumer sample as a whole, we analyzed the willingness to buy (WTB) of consumers for the twelve different iced coffee products by applying the mixed model ANOVA as described above. The residuals approximate a normal distribution quite well supporting the tests below for indicating the relative importance of the factors.

The ANOVA model is significant $(\mathrm{p}<0.01)$ which means that there are significant statistical differences on WTB among the twelve iced coffee products presented to consumers. Then, Tukey's test was computed to discover which of the 12 presented iced coffee products consumers were most willing to buy. The most preferred product is P11 (Latte, low calories, produced in Italy and at the lowest price) followed by P4 (Espresso, low calories, produced in Norway and at the lowest price) and P3 (Latte, low calories, produced in Norway and at medium price). Accordingly, no systematic preferences emerge in terms of iced coffee type and country of production. This hints to the presence of consumer segments with diverging preferences, as will be investigated below.

\section{Population effects}

\section{Main effects}

The mixed model ANOVA results shows that both calories and price present significant effects ( $\mathrm{p}$-values $<0.01$, while the factors coffee and origin are not statistically significant at a $5 \%$ level. The significant effects are estimated to be negative, that is to say that consumers on average prefer low calories and low prices to high calories and higher prices (Figure 2). Based on the fitted model, consumers' WTB increase by $12,6 \%$ ( 0.5 units on the 9-point WTB scale) when reducing calorie content from $90 \mathrm{kcal} / 100 \mathrm{ml}$ to 60 $\mathrm{kcal} / 100 \mathrm{ml}$ and consumers' WTB increase by $37.7 \%$ (1.5 units on the 9-point WTB scale) when reducing 


\section{Running title: CONSUMER PREFERENCES FOR ICED COFFEE PRODUCTS}

price from $23 \mathrm{NOK}$ to $17 \mathrm{NOK}$ per $250 \mathrm{ml}$ (Figure 2). These results indicate that there may be a market potential for calorie reduced iced coffee products. It is however important to note that in this experiment, product profiles were presented on-screen without involving tasting. Research studies have demonstrated that low calorie products often perform poorly in hedonic tests compared to their full calorie counterparts 208 (Ares, et al., 2008; Roininen, et al., 2000).

\section{Interaction effects}

210 Only one interaction between conjoint factors is significant: Calories*Price, confounded with 211 Coffee* Origin (p-values $<0.01)$. The confounding means that it is not statistically possible to identify 212 which of the two interactions is observed, presents both these potential interactions. Consumers on 213 average are more reluctant to pay increasing prices for iced coffee products at low calorie content, 214 decreasing their WTP faster than for high calorie content and has a preference for Espresso iced coffee is 215 associated with a preference for production in Norway. On the other hand, preferences for Latte iced 216 coffee are independent of production origin. Note that as both Calories and Price show significant main 217 effects on consumer's WTB, while neither Coffee nor Origin showed significant main effects, it is 218 reasonable to identify the observed interaction effect as that of Calories*Price.

\section{Preference heterogeneity and consumer segmentation}

\section{Coffee type and Origin segments}

222 In order to determine consumer segments based on individual preference patterns in the conjoint rating task, a PCA model was run on the data matrix of consumers' Willingness To Buy (WTB) for each product profile as described above. We identified four Principal Components (PCs): coffee type (on PC1, restituting $37 \%$ of the variance), price (on PC2, 24\%), origin (on PC3, 12\%) and calories (on PC4, 8\%). Further details can be found in SR1. Thus consumers mostly differed in their coffee type preferences, such that it is interesting to conduct a consumer segmentation on that attribute. Further details can be found in SR2. Figure 3 shows the PCA correlation loadings plot for PC1 and PC3, where distinct product groups appear according to coffee type and origin attribute levels.. We created manually four consumer 


\section{Running title: CONSUMER PREFERENCES FOR ICED COFFEE PRODUCTS}

segments directly corresponding to the distribution of consumers in the four quadrants. As the clusters were defined based on consumers' similarity of WTB for attributes coffee type and origin, they will be

232 referred to as "Latte/Italy" (26 consumers), "Espresso/Italy" (24 consumers), "Espresso/Norway" (30 233 consumers) and "Latte/Norway" (21 consumers).

\section{4}

\section{Segment characteristics}

\section{WTB product profiles}

The four consumer segments are presented by calculating their respective mean WTB values for each of the factors investigated (Figure 4a-d). The two Latte groups clearly prefer iced coffee "Latte" to "Espresso" and vice versa for the Espresso groups. All segments prefer low calories to high calories iced coffee while the production origin plays a role in segmenting consumers in the four identified groups, and finally all segments prefer lower prices. To describe the consumer segments by socio-demographic characteristics, warm coffee consumption habits and iced-coffee consumption habits, a PLS-DA approach was applied as described above. In the following, only statistically significant results are reported.

\section{Personal attributes}

Results indicates significant relationships between age and the first segment (Latte/Italy) and the fourth segment (Espresso/Norway) but in opposite directions. More specifically, younger consumers are more attracted to Latte iced coffee from Italy, while older consumers prefer Espresso iced coffee from Norway. In terms of general characteristics such as health conscious, ethnocentrism, taste, place of living (e.g. countryside, city), gender and BMI we did not detect any significant difference among the four segments.

\section{Warm coffee habits}

With regard to warm coffee consumption habits, four sub-groups of variables successfully discriminated the consumer segments: Warm coffee type, Cream \& sugar, Consumption frequency and Location. Results shows that from a general perspective there is a strong relationship between warm coffee habits 


\section{Running title: CONSUMER PREFERENCES FOR ICED COFFEE PRODUCTS}

and iced coffee preferences reflected in the segments belonging. For example, consumers in Espresso/Norway segment show the highest consumption of "Regular", "Espresso" and "Americano" warm coffee types, and the lowest consumption of "Latte". An opposite relationship has been found for segment "Latte/Italy". Further details can be found in SR3.

\section{Iced coffee habits}

The PLS-DA results indicate that none of the iced coffee characteristics investigated, such as when drinking during the day (e.g. wake up, afternoon, etc.), location of drinking (e.g. home, work, university, etc.), motivation of drinking (e.g. thirsty, energy, etc.), frequency consumption, how long drink, etc. significantly differentiated the four consumer segments. The questionnaire also investigated consumers' purchase habits in terms of brands and iced coffee types, with special emphasis on a Norwegian brand (A) and a foreign brand (B). Results show that consumers in Latte/Italy and Latte/Norway segments were regular purchasers of a Latte product from brand A, while this product was negatively linked to segment Espresso/Norway.

Consumers in segment Latte/Norway were also purchasers of a caramel flavored product from brand B, while the same product was significantly not characteristic of purchases by consumers in segments Espresso/Italy and Espresso/Norway. On the other hand, these groups typically purchased a caffeine-rich product from brand A which was not consumed by consumers in segments Latte/Italy and Latte/Norway. Conclusively, there is a clear consistence between consumers' iced coffee product choices in real life and their willingness-to-buy ratings from the conjoint experiment, which are reflected in their segment belonging.

\section{CONCLUSIONS}

This study aimed at exploring consumers' iced coffee consumption habits and investigating consumer preferences for extrinsic attributes of iced coffee. Since our aim was not to provide representative data for all the country, but rather it was to explore the relationships among variables (e.g. coffee habits, purchase 


\section{Running title: CONSUMER PREFERENCES FOR ICED COFFEE PRODUCTS}

motivations, etc.) we state a positive argument for the validity of our results related to sample size $(\mathrm{N}=101)$. Experience from literature shows that above $\mathrm{N}=100$ consumers a sample is good enough for detecting important effects. This validity is also supported by the fact that the results (ANOVA) are significant. A larger sample was impossible for economic reasons while we did not provide any economic benefits for consumers, therefore no social bias. Results show that the most preferred products for the consumer sample as a whole were low price - low calorie products. This indicates that there may be a market potential for calorie reduced iced coffee products. Further, four consumer segments were identified that differed in coffee type and production origin preferences: Latte/Italy, Latte/Norway, Espresso/Italy and Espresso/Norway. In terms of personal and socio-demographic characteristics attributes investigated, only age has a significant effect on consumer's WTB various coffee types: younger consumers present higher WTB for "Latte" products while older consumers show higher WTB for "Espresso" and vice versa. None of the other personal characteristics investigated, such as health conscious, ethnocentrism, taste, place of living (e.g. countryside, city), gender and BMI present significant effect on WTB of the four segments.

The two consumer groups attracted by the espresso mock-ups reported a high warm coffee consumption and typically purchase iced coffee products with a high caffeine content. The two consumer groups attracted by the latte mock-ups reported lower warm coffee consumption levels, usually add milk, cream and/or sugar in their coffee, and typically purchase latte iced coffee products with low caffeine content and flavoured iced coffee products. Thus, there is a clear consistence between consumers' attributes preferences in the conjoint experiment, their real life choices in terms of iced coffee and their warm coffee consumption habits.

Finally, since we did not find in the literature any similar studies about iced coffee it is not possible to compare our findings with other researches. Future researches maybe conduct similar studies in other countries to compare the results and investigate whether the willingness to buy for low calorie iced coffee products persists after product tasting and product exposure over time. Therefore, a final recommendation for further research is also to refine a methodology that incorporate sensory characteristics within conjoint 


\section{Running title: CONSUMER PREFERENCES FOR ICED COFFEE PRODUCTS}

analysis in order to provide more valuable information and asset for the food industry (De Pelsmaeker et 309 al., 2013).

\section{ACKNOWLEDGEMENTS}

312 Financial support from the Research Council of Norway for the YGGDRASIL mobility program 2012313 2013: Project Number 219787/F11 is acknowledged. The research was conducted in Norway in the 314 framework of the FOODCHOICE project that is a user-driven project funded by the Research Council of 315 Norway and focuses on method development within consumer research.

\section{REFERENCES}

318 Annunziata, A., \& Vecchio, R. (2013). Consumer perception of functional foods: A conjoint analysis with 319 probiotics. Food Quality and Preference, 28(1), 348-355.

320 Ares, G., Giménez, A., \& Gámbaro, A. (2008). Understanding consumers’ perception of conventional and 321 functional yogurts using word association and hard laddering. Food Quality and Preference, 19(7), 636322643.

323 Cadena, R. S., Cruz, A. G., Faria, J. A. F., \& Bolini, H. M. A. (2012). Reduced fat and sugar vanilla ice 324 creams: Sensory profiling and external preference mapping. Journal of dairy science,95(9):4842-4850.

325 Claret, A., Guerrero, L., Aguirre, E., Rincón, L., Hernández, M. D., Martínez, I., ... Rodríguez326 Rodríguez, C. (2012). Consumer preferences for sea fish using conjoint analysis: Exploratory study of the 327 importance of country of origin, obtaining method, storage conditions and purchasing price. Food Quality 328 and Preference, 26(2), 259-266.

329 Cox, D. N., Evans, G., \& Lease, H. J. (2007). The influence of information and beliefs about technology 330 on the acceptance of novel food technologies: A conjoint study of farmed prawn concepts. Food Quality 331 and Preference, 18(5), 813-823. 


\section{Running title: CONSUMER PREFERENCES FOR ICED COFFEE PRODUCTS}

332 Cruz, A. G., Cadena, R. S., Faria, J. A. F., Oliveria, C. A. F., Cavalcanti, R. N., Bona, E., ... DA SILVA,

333 M. A. A. P. (2011). Consumer acceptability and purchase intent of probiotic yoghurt with added glucose 334 oxidase using sensometrics, artificial neural networks and logistic regression. International Journal of 335 Dairy Technology, 64(4), 549-556.

336 De Pelsmacker, P., Driesen, L., \& Rayp, G. (2005). Do Consumers Care about Ethics? Willingness to Pay 337 for Fair-Trade Coffee. Journal of Consumer Affairs, 39(2), 363-385.

338 De Pelsmaeker, S., Dewettinck, K., \& Gellynck, X. (2013). The possibility of using tasting as a 339 presentation method for sensory stimuli in conjoint analysis. Trends in Food Science \& Technology, $340 \quad 29(2), 108-115$.

341 Endrizzi, I., Menichelli, E., Johansen, S. B., Olsen, N. V., \& Næs, T. (2011). Handling of individual 342 differences in rating-based conjoint analysis. Food Quality and Preference, 22(3), 241-254.

343 Green, P. E., \& Srinivasan, V. (1978). Conjoint Analysis in Consumer Research: Issues and Outlook. 344 Journal of Consumer Research, 5(2), 103-123.

345 International Coffee Organisation. (2011). International Coffee Organisation.

346 Næs, T., Almli, V. L., Bølling Johansen, S., \& Hersleth, M. (2010). Alternative methods for combining 347 design variables and consumer preference with information about attitudes and demographics in conjoint 348 analysis. Food Quality and Preference, 21(4), 368-378.

349 Næs, T., Brockhoff, P., \& Tomic, O. (2010). Statistics for sensory and consumer science. (Wiley, Ed.). 350 Chichester, UK.

351 Petit, C., \& Sieffermann, J. M. (2007). Testing consumer preferences for iced-coffee: Does the drinking 352 environment have any influence? Food Quality and Preference, 18(1), 161-172.

353 Raynolds, L. T. (2004). The globalisation of organic agro-food networks. World Development, 32(5), $354 \quad 725-743$.

355 Roininen, K., Lähteenmäki, L., \& Tuorila, H. (2000). An application of means-end chain approach to 356 consumers' orientation to health and hedonic characteristics of foods. Ecology of Food and Nutrition, $357 \quad 39(1), 61-81$. 
Running title: CONSUMER PREFERENCES FOR ICED COFFEE PRODUCTS

358 Rozin, P., \& Cines, B. M. (1982). Ethnic differences in coffee use and attitudes to coffee. Ecology of 359 Food and Nutrition, 12, 79-88.

360 Saito, H., \& Saito, Y. (2013). Motivations for Local Food Demand by Japanese Consumers: A Conjoint 361 Analysis with Reference-Point Effects. Agribusiness, 29(2), 147-161.

362 Souza, S. S., Cruz, A. G., Walter, E. H. M., Faria, J. A. F., Celeghini, R. M. S., Ferreira, M. M. C., ... 363 Sant'Ana, A. de S. (2011). Monitoring the authenticity of Brazilian UHT milk: A chemometric approach. 364 Food Chemistry, 124(2), 692-695. 
Running title: CONSUMER PREFERENCES FOR ICED COFFEE PRODUCTS

367

368

369

370

371

372

373

374

375

376

377

378

379

380

381

382

383

384

385

386

387

388

389

390

391

392

393

71

\section{4}

\section{TABLE LEGENDS}

Table 1 - Hypothetical iced coffee profiles obtained by means of the orthogonal array design.

(1)

72

75


Running title: CONSUMER PREFERENCES FOR ICED COFFEE PRODUCTS

Table 1

\begin{tabular}{ccccc}
\hline PRODUCT & TYPE OF COFFEE & $\begin{array}{c}\text { CALORIES } \\
(\mathrm{kcal} / 100 \mathrm{ml})\end{array}$ & COUNTRY OF ORIGIN & PRICE (NOK) \\
\hline $\mathbf{1}$ & Espresso & 90 & Italy & Kr. 29,-- \\
$\mathbf{2}$ & Latte & 90 & Norway & Kr. 23,- \\
$\mathbf{3}$ & Latte & 60 & Norway & Kr. 23,- \\
$\mathbf{4}$ & Espresso & 60 & Norway & Kr. 17,- \\
$\mathbf{5}$ & Latte & 90 & Norway & Kr. 29,- \\
$\mathbf{6}$ & Espresso & 60 & Norway & Kr. 29,- \\
$\mathbf{7}$ & Espresso & 90 & Norway & Kr. 17,- \\
$\mathbf{8}$ & Latte & 90 & Italy & Kr. 17,- \\
$\mathbf{9}$ & Latte & 60 & Italy & Kr. 29,- \\
$\mathbf{1 0}$ & Espresso & 90 & Italy & Kr. 23,- \\
$\mathbf{1 1}$ & Latte & 60 & Italy & Kr. 17,- \\
$\mathbf{1 2}$ & Espresso & 60 & Italy & Kr. 23,- \\
\hline
\end{tabular}

396 
Running title: CONSUMER PREFERENCES FOR ICED COFFEE PRODUCTS

400 Figure 1 - Iced coffee consumption motivations expressed in percentage frequency with standard 401 errors

402 Figure 2- Main effects of the four factors in conjoint rating. Calories and Price have significant 403 main effects while Coffee and Origin do not.

404 Figure 3 - PCA correlation loadings showing sample and consumer distributions according to 405 attributes Coffee (PC1) and Origin (PC3)

406 Figure 4 - Average WTB value and standard errors on mock-up products varying in attributes a)

407 Coffee type, b) Calories, c) Origin and d) Price for each of the four consumer segments 
Running title: CONSUMER PREFERENCES FOR ICED COFFEE PRODUCTS

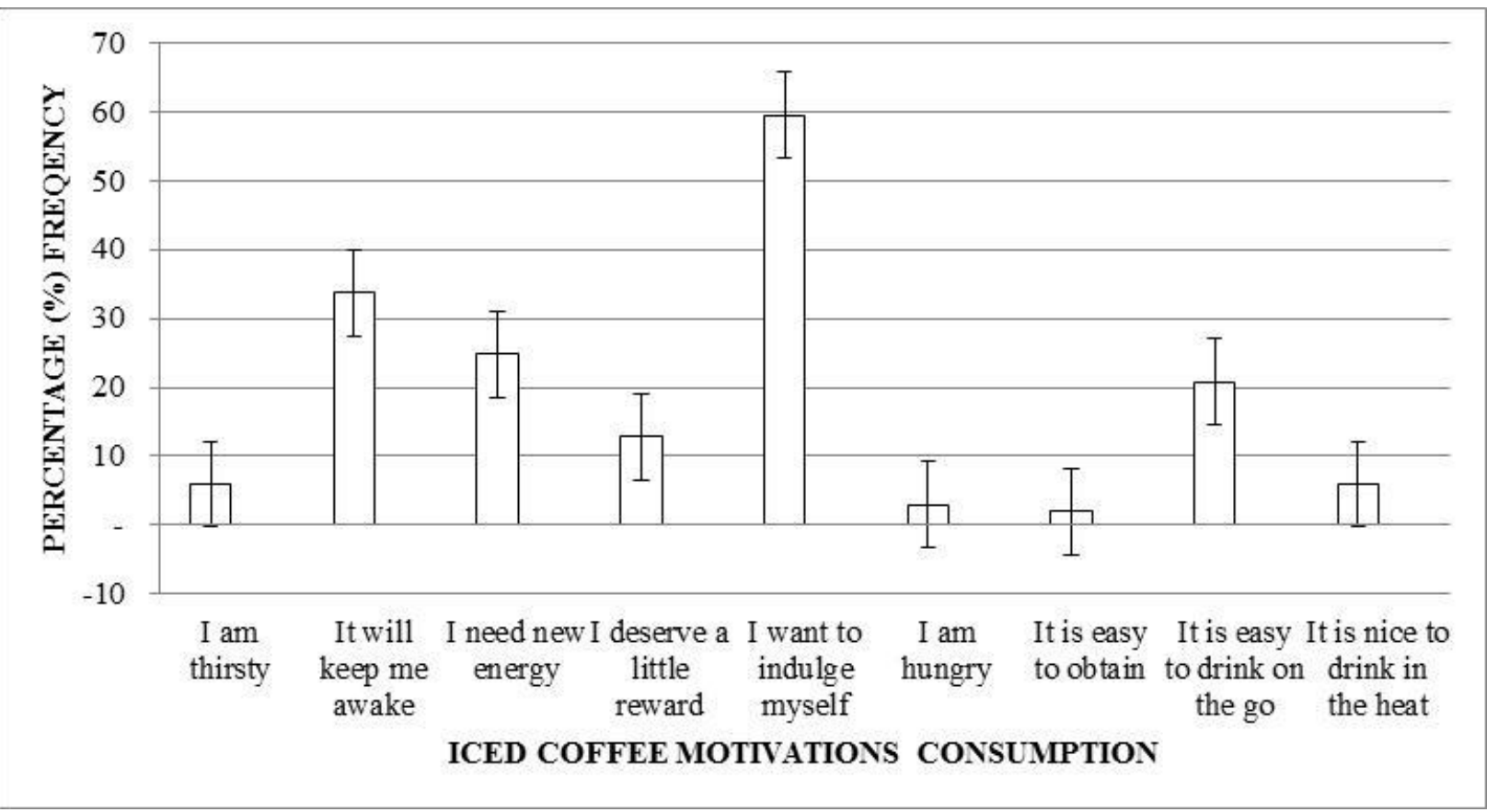

424

Figure 1

426

427

428

429

430

431

432

433

434

435

436

437

438

439

440

441

442

443 
Running title: CONSUMER PREFERENCES FOR ICED COFFEE PRODUCTS

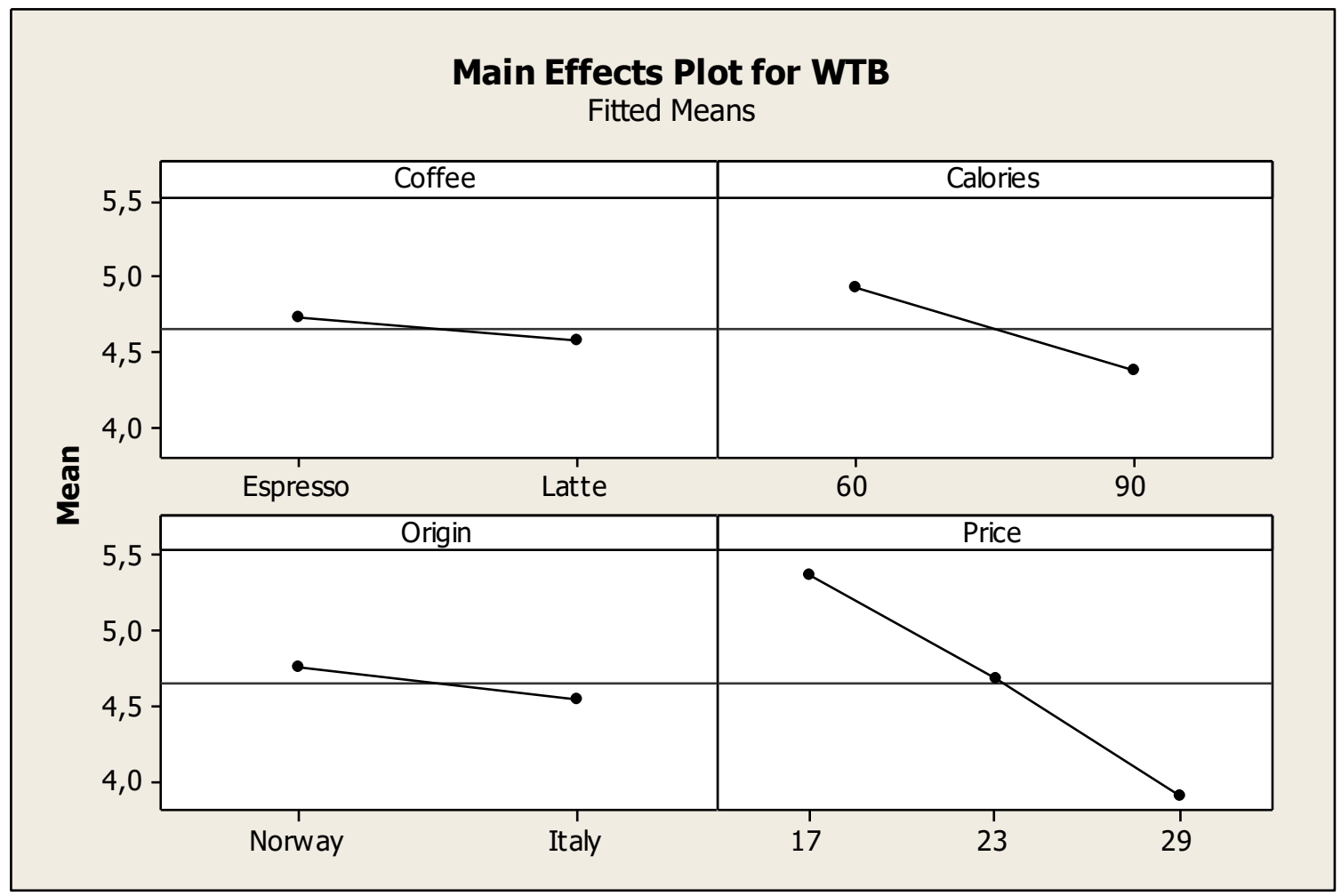

444

Figure 2 
Running title: CONSUMER PREFERENCES FOR ICED COFFEE PRODUCTS

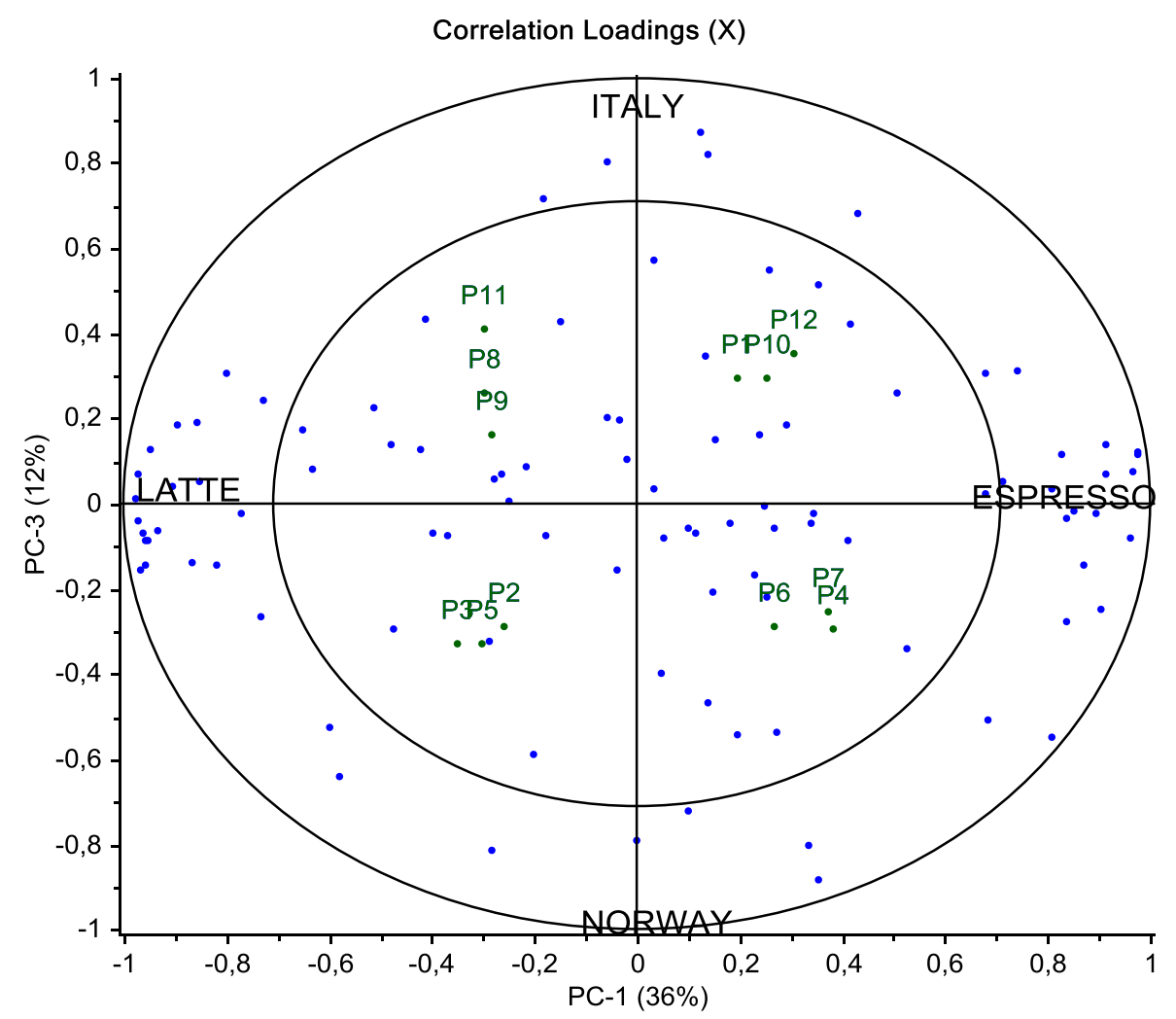

461

$462 \quad$ Figure 3

463

464

465

466

467

468

469

470

471

472

473

474

475 
Running title: CONSUMER PREFERENCES FOR ICED COFFEE PRODUCTS

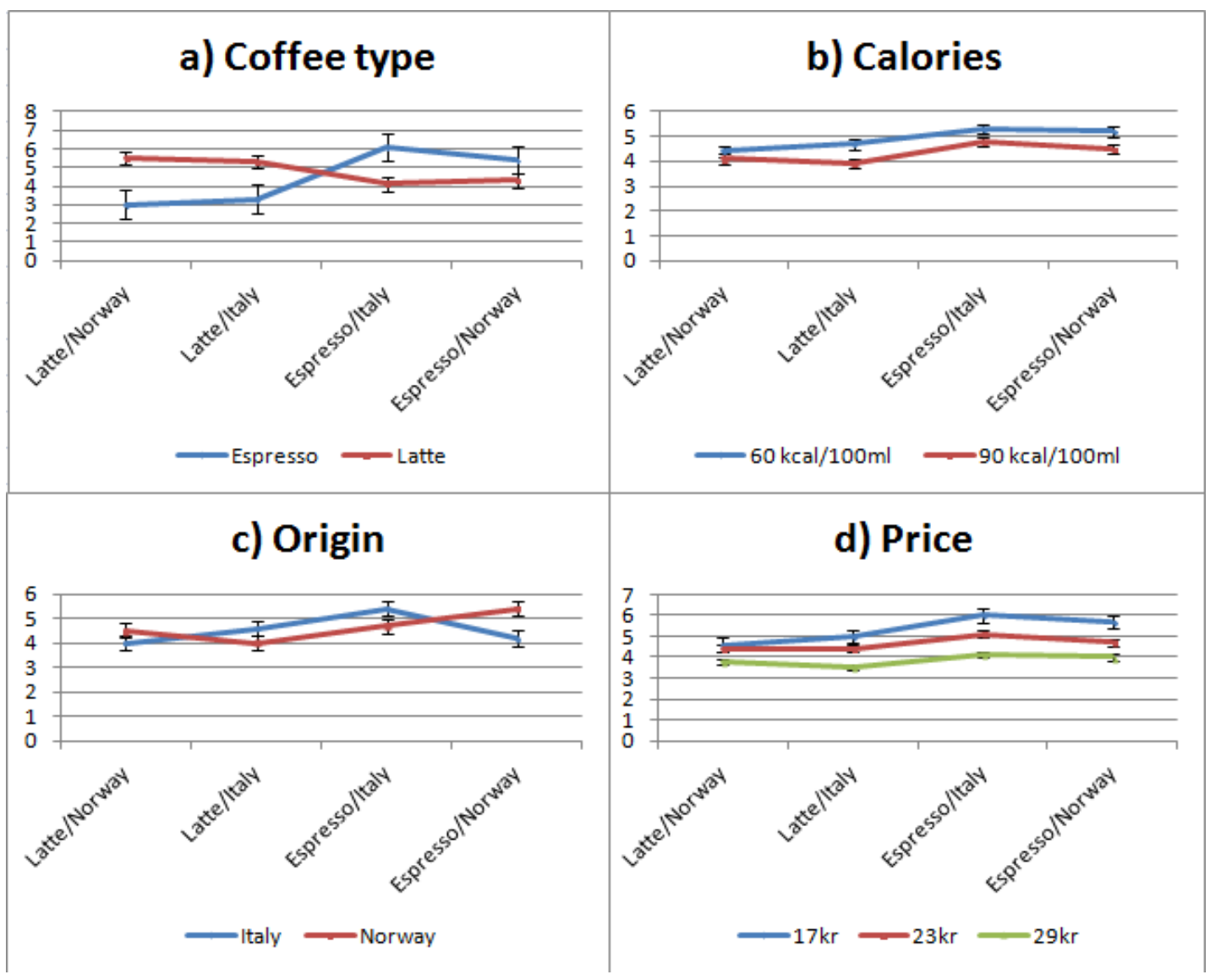

Figure 4 


\section{SUPPLEMENTARY TEXT}

\section{SUPPLEMENTARY MATERIAL AND METHODS}

\section{SM1 - Mixed model ANOVA}

ANalysis Of VAriance (ANOVA) is one of the most used methodologies when investigating product differences in sensory and consumer studies since the main purpose of this method is to identify and quantify the factors that are responsible for the variability of the response (Næs, Brockhoff, et al., 2010). In the model applied, note that interactions Price*Calories and Price*Coffee are confounded with Coffee* Origin and Price*Origin, respectively.

\section{SM 2 - Segmentation details}

In order to conduct a consumer segmentation based on individual preferences, PCA was applied on the WTB matrix presenting product profiles in rows $(\mathrm{P} 1, \mathrm{P} 2, \ldots . \mathrm{P} 12)$ and consumers in columns $(\mathrm{C} 1$, C2....C101) (Table S1). The data were centered and scaled column wise to correct for different scale usage across consumers. Segmentation was performed by visual delimitation of consumer groups based on the PCA loadings of selected principal components. Defining groups visually from the consumer preference patterns displayed in PCA ensures that consumers sharing the same attribute preferences fall into the same segment, thus facilitating results interpretation.

Then, common socio-demographic and behavioural characteristics were investigated within segments by performing Partial Least Squares Discriminant Analysis (PLS-DA). Endrizzi et al., (2011) define PLSDA as a method that relates acceptance patterns to external characteristics by identifying segments and relate them to the consumer characteristics using some type of discriminant analysis (PLS discriminant analysis; see e.g. (Barker \& Rayens, 2003). 
Running title: CONSUMER PREFERENCES FOR ICED COFFEE PRODUCTS

PLS-DA was conducted on the behavioural, coffee habits and socio-demographics questionnaire matrix

509 presenting consumers in rows and questionnaire items in columns. The dependent variables were binary

510 variables $(0 / 1)$ coding for segment belonging (Table S2). Cross-validation and significance testing by

511 jack-knifing at 5\% level were used in order to detect significant predictor variables (Martens \& Martens,

512 2000). As the questionnaire included several blocks of unrelated items (iced coffee habits, socio-

513 demographics...), there is a risk of obtaining somewhat spurious conclusions. This was addressed by

514 running several PLS-DA models, including either all blocks or selected subsets of blocks. Predictor

515 variables that systematically showed significance in different models are reported here, while predictor

516 variables with no stability across models were withdrawn. PCA and PLS-DA were conducted in the

517 multivariate statistics software package The Unscrambler X 10.2 (Camo Software AS, Norway). 


\section{Running title: CONSUMER PREFERENCES FOR ICED COFFEE PRODUCTS}

\section{SUPPLEMENTARY RESULTS}

\section{SR 1 - Coffee type and Origin segments}

532 Consumers did not really differ in their preferences for calorie content, indicating that the mean 533 preference for low calorie content highlighted by the ANOVA is valid at individual level as well. As 534 expected, results along PC2 showed a large majority of consumers projected in the direction of low price 535 preferences (results not shown).

$537 \quad$ SR2 - Coffee type and Origin segments

538 As a possible interaction of Coffee*Origin was detected in the mixed model ANOVA, consumer 539 segments were defined on a criteria of common WTB values regarding attributes Coffee type and Origin.

\section{$541 \quad$ SR3 - Warm coffee habits}

542 Firstly, consumers in segment Espresso/Norway show the highest consumption of "Regular", "Espresso" 543 and "Americano" warm coffee types, and the lowest consumption of "Latte". An opposite relationship 544 has been found for segment "Latte/Italy" (Figure S1). Secondly, consumers in segment Espresso/Norway 545 typically consume warm coffee without any milk, cream or sugar, while consumers in segments 546 Latte/Italy and Latte/Norway add such ingredients. Thirdly, consumers in segments Espresso/Italy and 547 Espresso/Norway report the highest consumption frequency of warm coffee while consumers in segment 548 Latte/Italy show the lowest consumption frequency. Finally, consumers in segments Espresso/Italy and 549 Espresso/Norway typically report drinking warm coffee at their workplace or university, while consumers 550 in segment Latte/Italy are characterized by not consuming warm coffee in these locations. These results 551 are illustrated in Figure S1.

\section{REFERENCES}


Running title: CONSUMER PREFERENCES FOR ICED COFFEE PRODUCTS

553 Barker, M., \& Rayens, W. (2003). Partial least squares for discrimination. Journal of Chemometrics, $554 \quad 17(3), 166-173$.

555 Endrizzi, I., Menichelli, E., Johansen, S. B., Olsen, N. V., \& Næs, T. (2011). Handling of individual 556 differences in rating-based conjoint analysis. Food Quality and Preference, 22(3), 241-254.

557 Martens, H., \& Martens, M. (2000). Modified Jack-knife estimation of parameter uncertainty in bilinear 558 modelling by partial least squares regression (PLSR). Food Quality and Preference, 11(1-2), 5-16.

559 Næs, T., Brockhoff, P., \& Tomic, O. (2010). Statistics for sensory and consumer science. (Wiley, Ed.). 560 Chichester, UK. 
Running title: CONSUMER PREFERENCES FOR ICED COFFEE PRODUCTS

565

566 Table S1 - Structure of PCA data matrix for willingness to buy (WTB)

567 Table S2 - Structure of PLS-DA matrix for consumer segments description 
Running title: CONSUMER PREFERENCES FOR ICED COFFEE PRODUCTS

592 Table S1 - Structure of PCA data matrix for willingness to buy (WTB).

\begin{tabular}{|c|c|c|c|c|c|c|c|c|c|c|c|}
\hline & \multicolumn{5}{|c|}{ Product dummies } & \multicolumn{6}{|c|}{ Consumers } \\
\hline Products & P1 & P2 & P3 & $\ldots$ & P12 & C1 & C2 & C3 & C4 & $\ldots$ & C101 \\
\hline P1 & 1 & 0 & 0 & $\ldots$ & 0 & & & & & \multirow{5}{*}{ WTB } & \\
\hline $\mathbf{P 2}$ & 0 & 1 & 0 & $\ldots$ & 0 & & & & & & \\
\hline P3 & 1 & 0 & 1 & $\ldots$ & 0 & & & & & & \\
\hline$\ldots$ & $\ldots$ & $\ldots$ & $\ldots$ & $\ldots$ & $\ldots$ & & & & & & \\
\hline P12 & 0 & 0 & 0 & $\ldots$ & 1 & & & & & & \\
\hline
\end{tabular}


Running title: CONSUMER PREFERENCES FOR ICED COFFEE PRODUCTS

594 Table S2 - Structure of PLS-DA matrix for segments description

\begin{tabular}{|c|c|c|c|c|c|c|c|}
\hline \multirow[b]{2}{*}{ Consumers } & \multicolumn{4}{|c|}{$\begin{array}{c}\text { Y: dependent variables } \\
\text { (Binary variables coding for segment } \\
\text { belonging) }\end{array}$} & \multicolumn{3}{|c|}{$\mathrm{X}$ : independent variables } \\
\hline & $\begin{array}{l}\text { Latte/ } \\
\text { Italy }\end{array}$ & $\begin{array}{c}\text { Latte/ } \\
\text { Norway }\end{array}$ & $\begin{array}{l}\text { Espresso/ } \\
\text { Italy }\end{array}$ & $\begin{array}{l}\text { Espresso/ } \\
\text { Norway }\end{array}$ & $\begin{array}{l}\text { Coffee } \\
\text { habits }\end{array}$ & $\begin{array}{c}\text { Iced coffee } \\
\text { habits }\end{array}$ & $\begin{array}{c}\text { Socio- } \\
\text { demographics }\end{array}$ \\
\hline C1 & 1 & $\mathbf{0}$ & $\mathbf{0}$ & $\mathbf{0}$ & \multirow{6}{*}{\multicolumn{3}{|c|}{ Questionnaire items }} \\
\hline $\mathrm{C2}$ & $\mathbf{0}$ & $\mathbf{0}$ & 1 & $\mathbf{0}$ & & & \\
\hline C3 & 1 & $\mathbf{0}$ & $\mathbf{0}$ & $\mathbf{0}$ & & & \\
\hline $\mathrm{C4}$ & $\mathbf{0}$ & $\mathbf{1}$ & $\mathbf{0}$ & $\mathbf{0}$ & & & \\
\hline$\ldots$ & ... & $\ldots$ & ... & ... & & & \\
\hline C101 & $\mathbf{0}$ & $\mathbf{0}$ & $\mathbf{0}$ & 1 & & & \\
\hline
\end{tabular}


Running title: CONSUMER PREFERENCES FOR ICED COFFEE PRODUCTS 
Running title: CONSUMER PREFERENCES FOR ICED COFFEE PRODUCTS

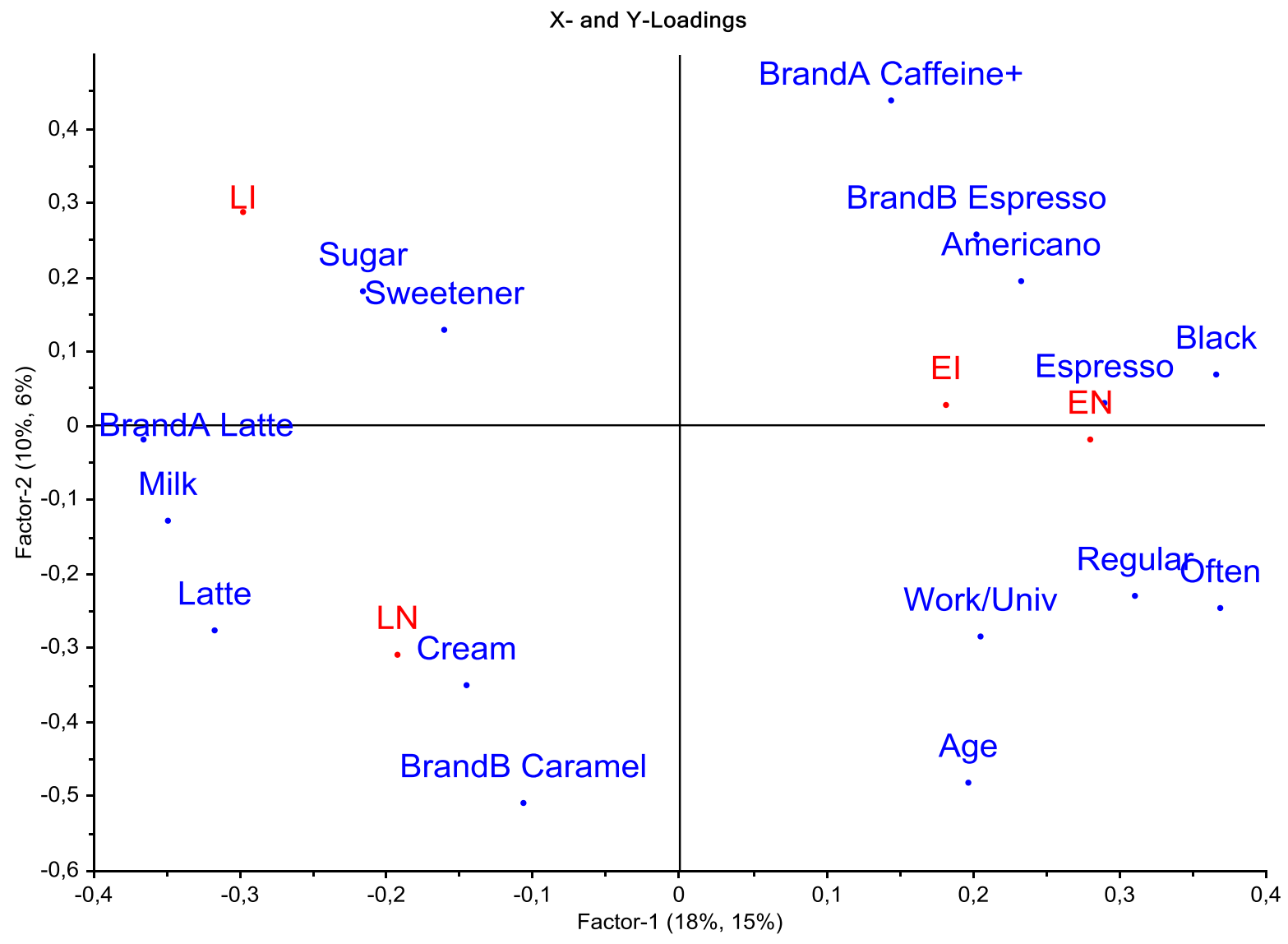

629

$630 \quad$ Figure $\mathbf{S 1}$

631

632 
Running title: CONSUMER PREFERENCES FOR ICED COFFEE PRODUCTS

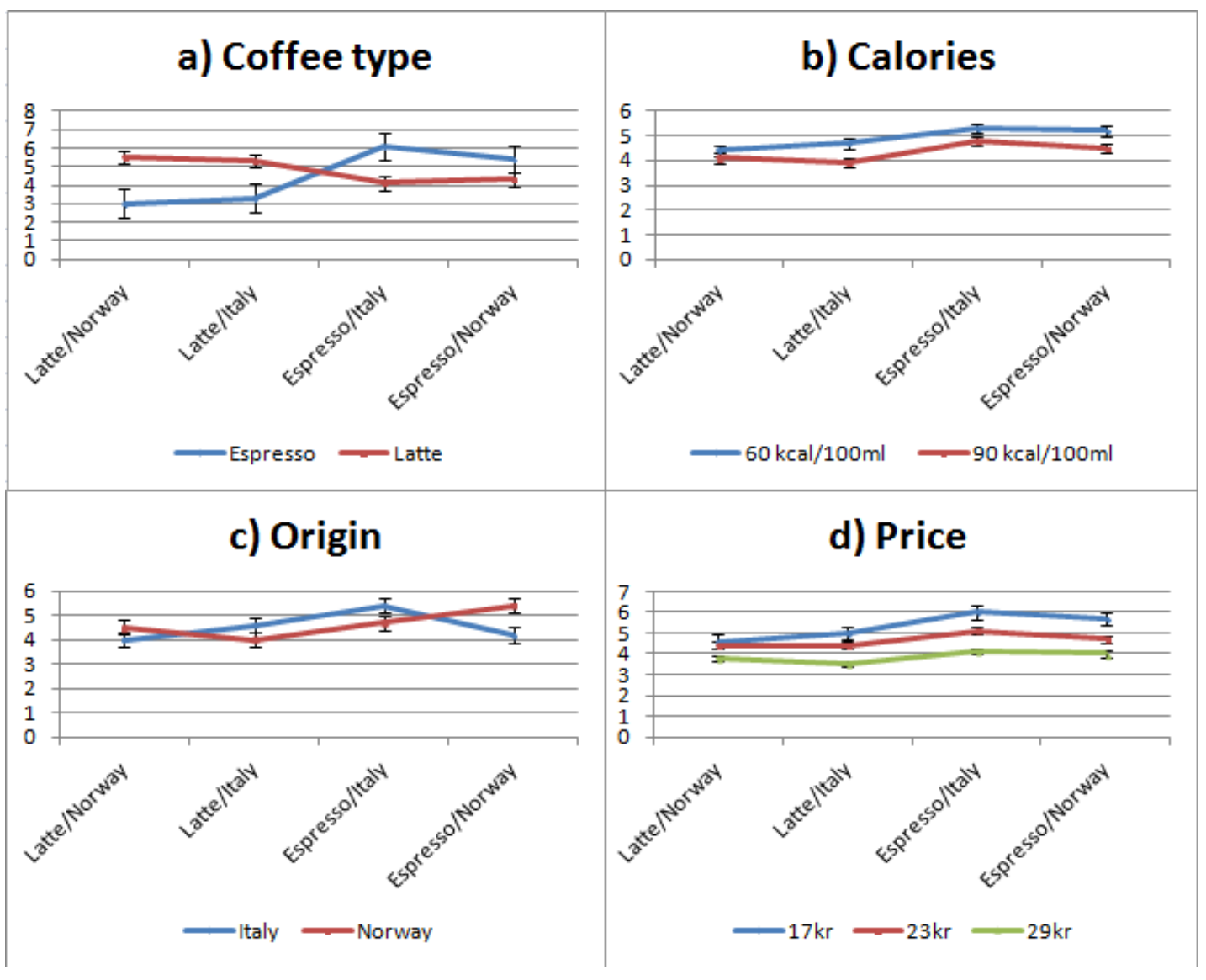

633

$634 \quad$ Figure S2

635

636

637

638

639

640

641

642

643

644 